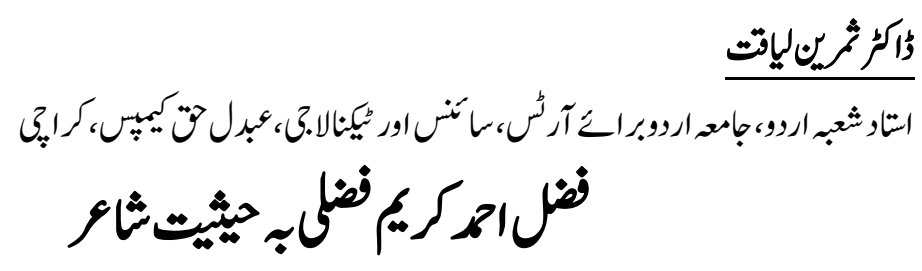

Dr. Samreen Liaquat

Assistant Professor Department of Urdu, Federal Urdu University of Arts, Science and Technology, Abdul Haq campus, Karachi.

\title{
Fazal Ahmad Karim Fazli as a poet
}

Poet and novelist Fazal Ahmad Karim Fazli was born on November 4, 1906 in Bahraich (Uttar Pradesh) and died on December 17, 1981 in Karachi. Educated at Allahabad and Oxford University. He held many important government posts in Bengal. After partition, he came to Pakistan and served as the Secretary, Department of Education, Government of East Pakistan. For some time he was also the Secretary of the Ministry of Kashmir Affairs. After retiring, Fazli made several films in Karachi. In 1951, at the invitation of the US government, he lectured as a guest lecturer in various US universities. "Until Blood and Liver" and "Until Magic" are his novels which made him famous but Fazli worked in both poetry and prose genres. His poetry collections Naghma Zindagi and Chashma Ghazal were published. He also recited a large number of poems on national and national themes. Fazli is a respected name in ghazal. In his ghazals, there are good examples of expressions of joy, sorrow, sadness, delicate symbols and allusions of love and emotions. This article is about his poetry.

Keywords: Fazal Ahmad Karim Fazli, Vrdu Poet, Vrdu Poetry.

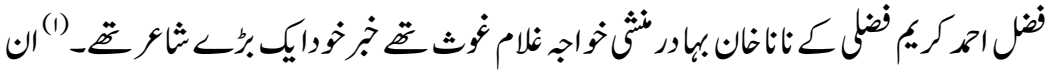

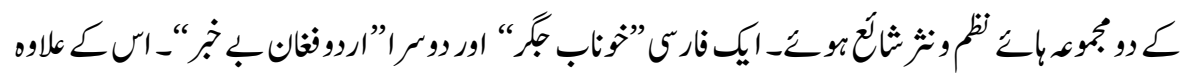

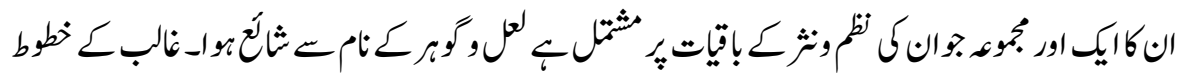

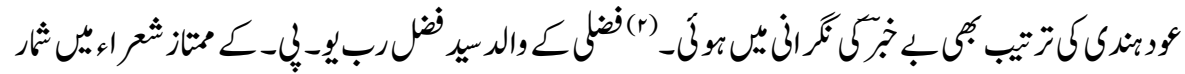

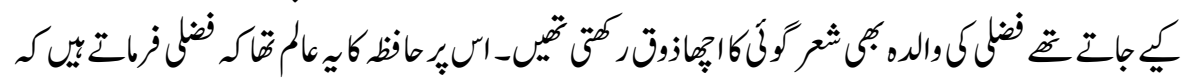




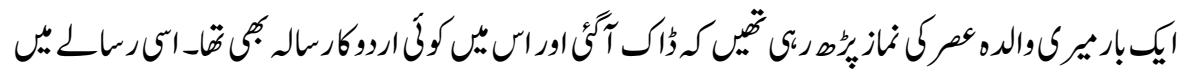

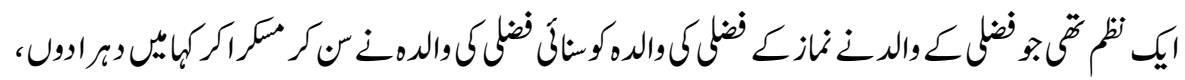

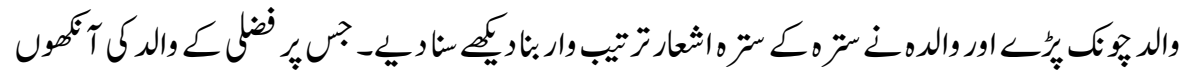

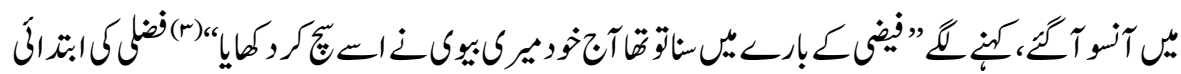

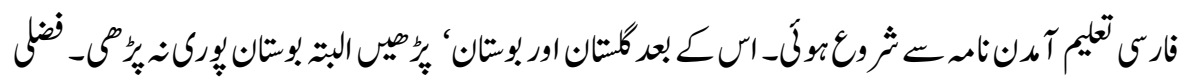

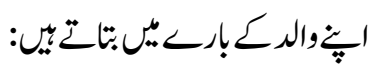

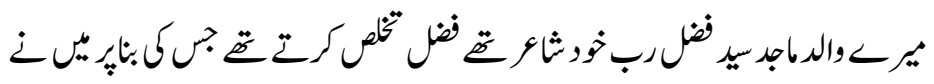

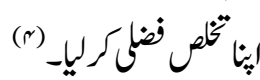

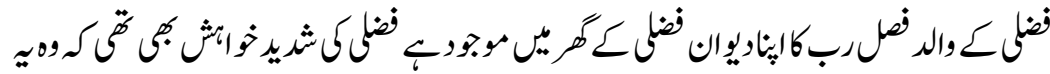

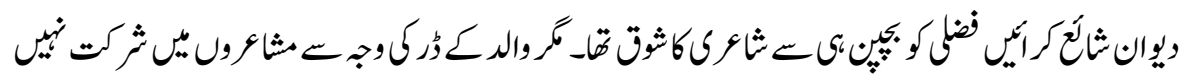

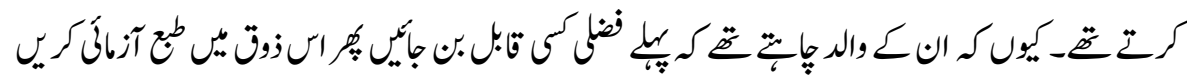

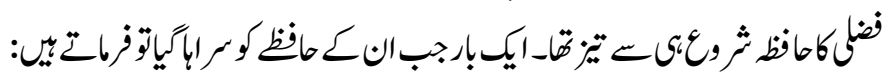

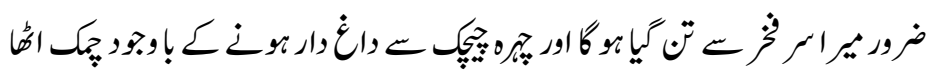

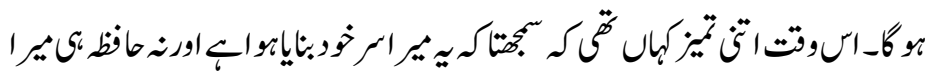

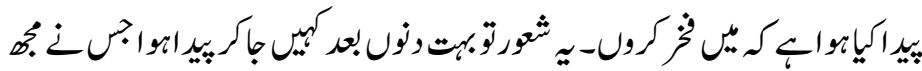

(ه)

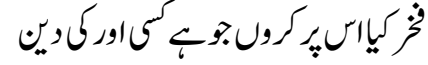

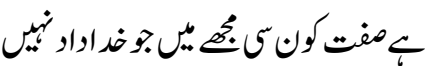

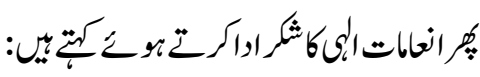

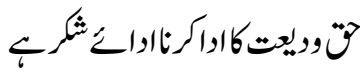

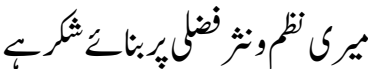

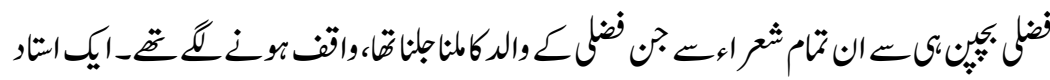

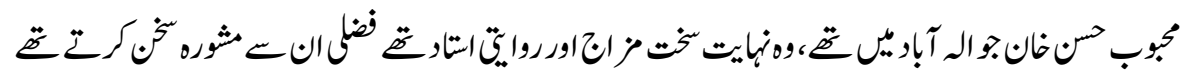




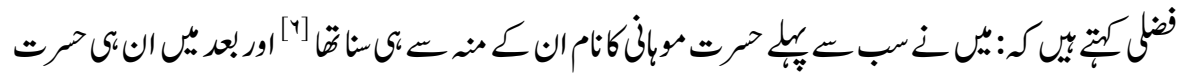

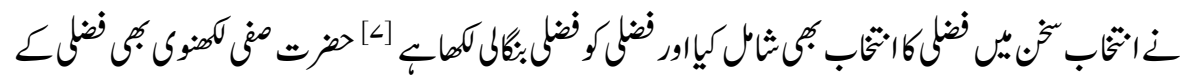

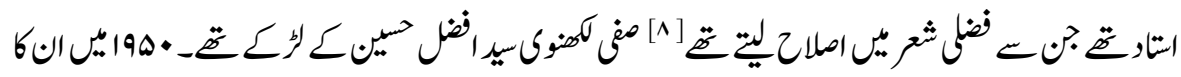

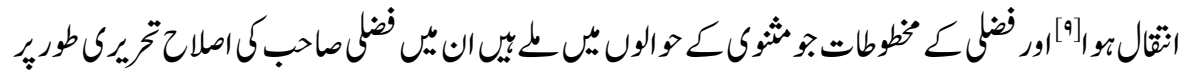

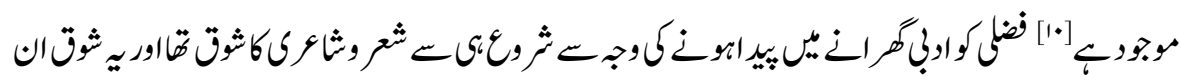

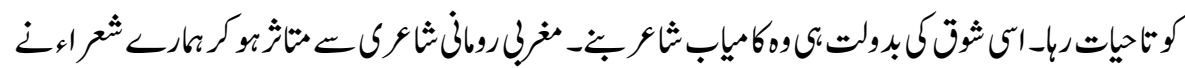

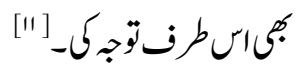

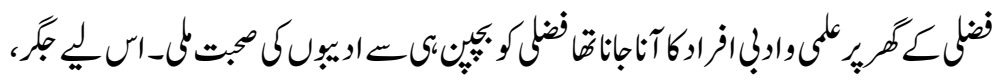

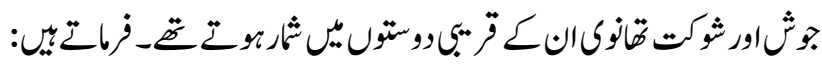

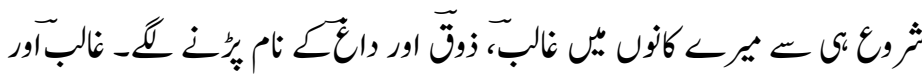

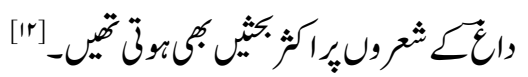

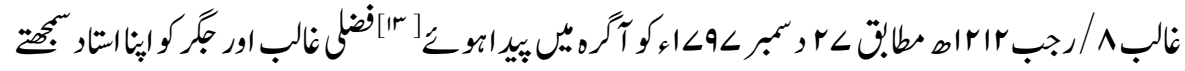

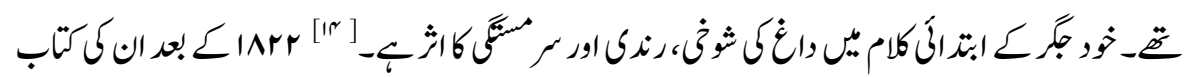

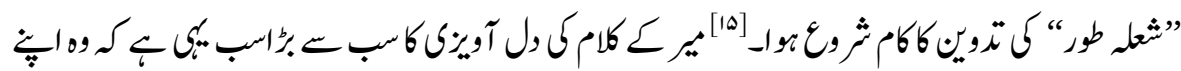

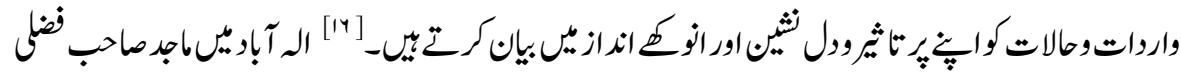

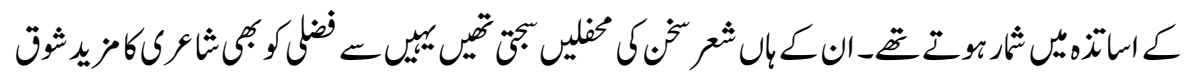

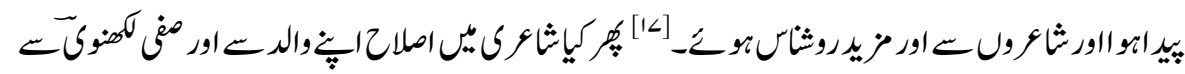

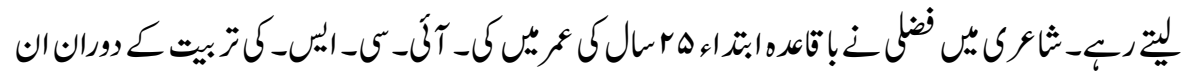

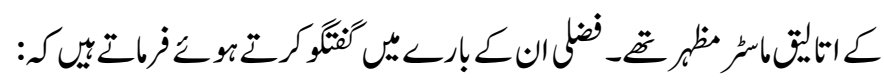

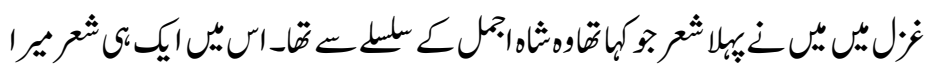

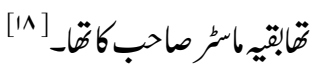

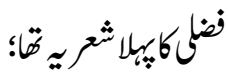

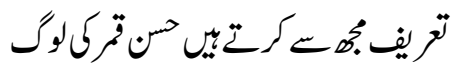




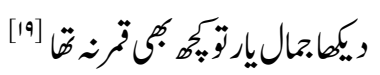

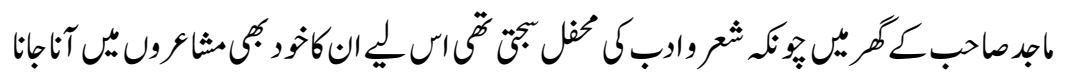

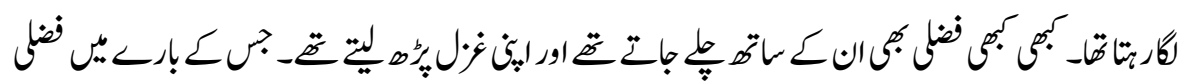

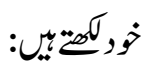

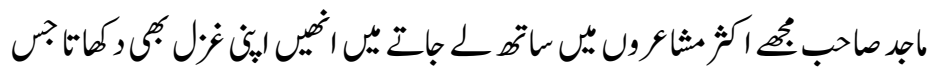

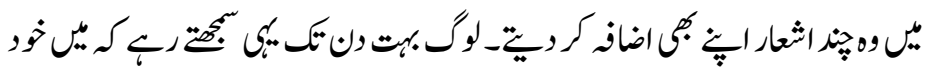

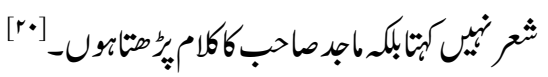

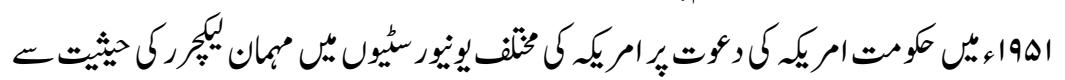

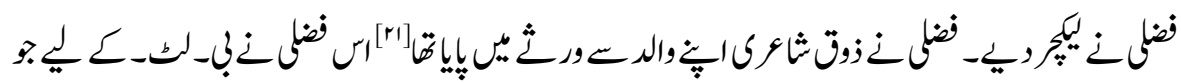

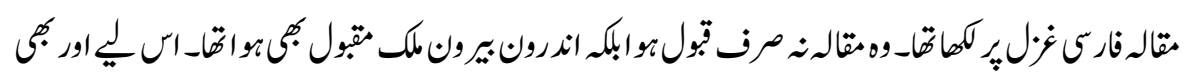

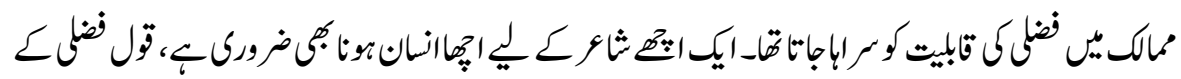

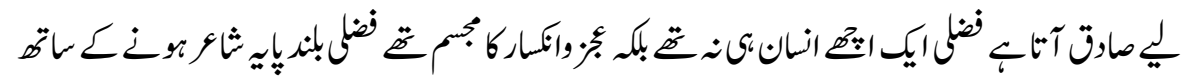

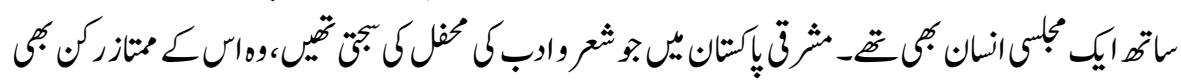

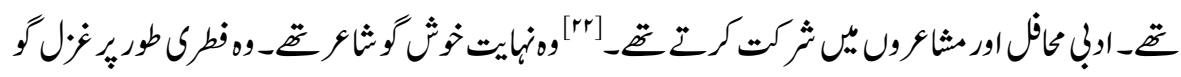

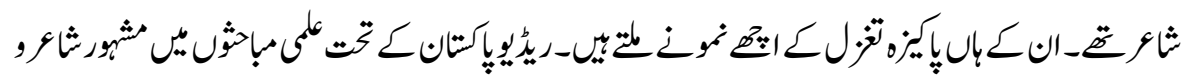

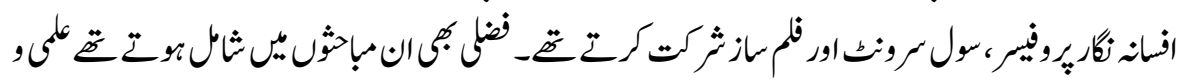

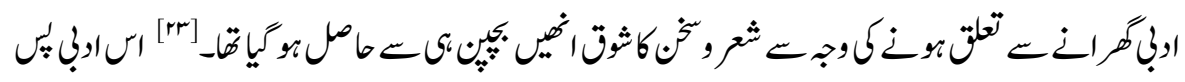

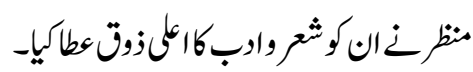

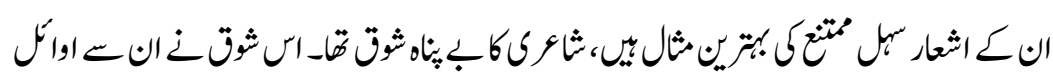

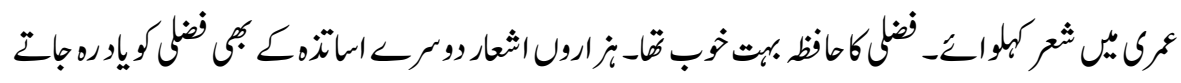

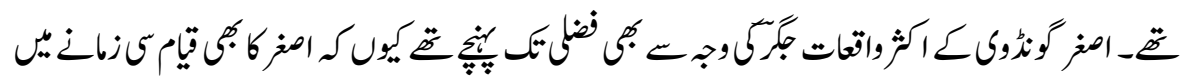

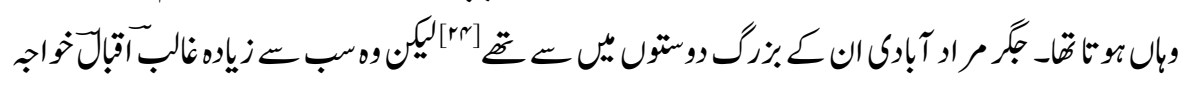

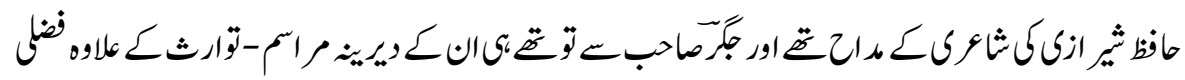




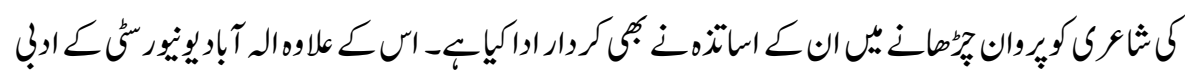

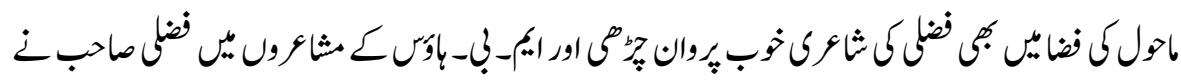

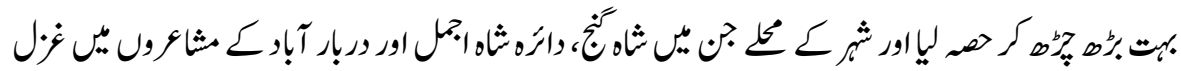

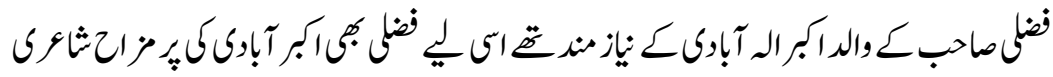

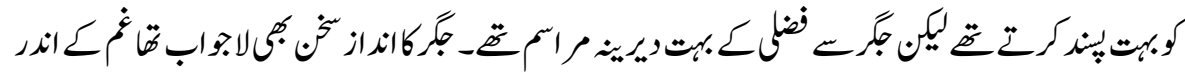

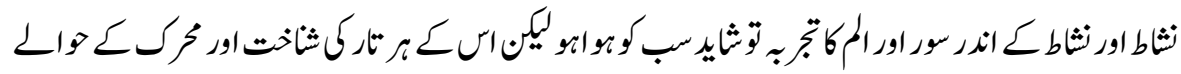

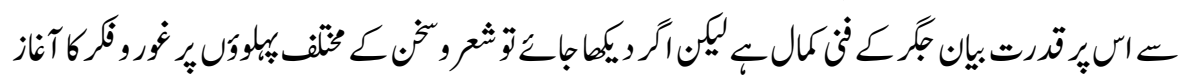

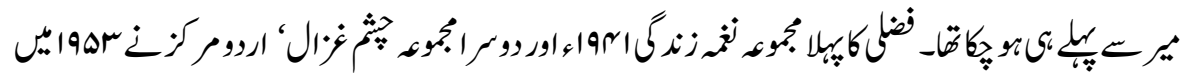

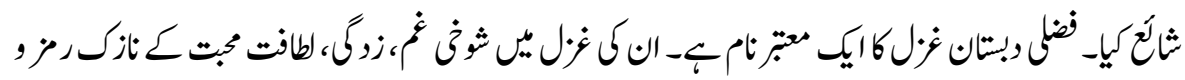

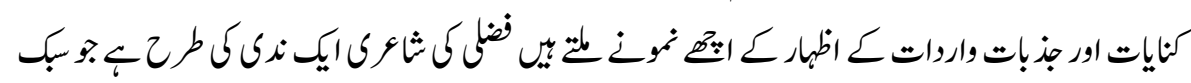

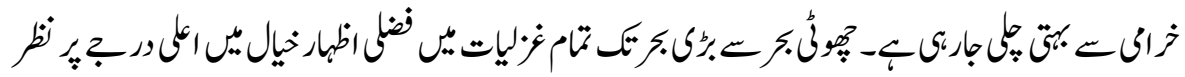

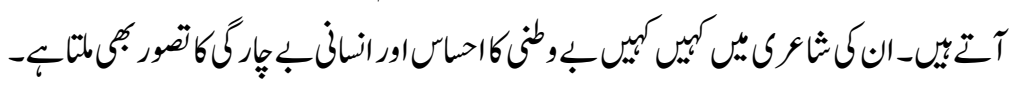

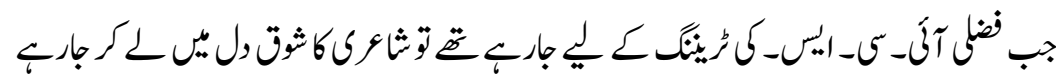

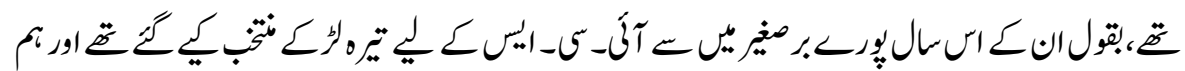

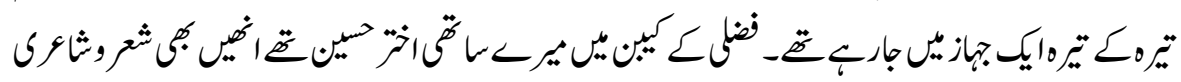

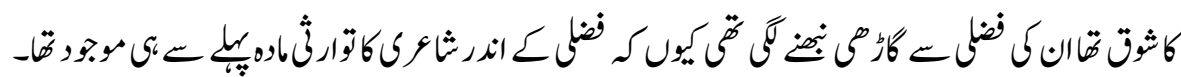

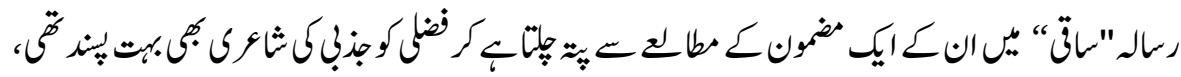

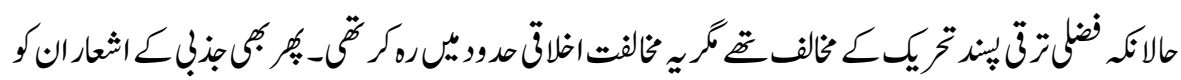

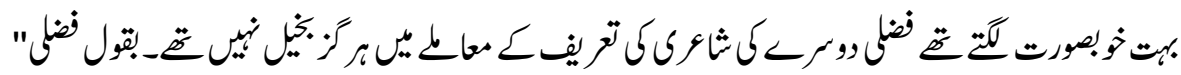

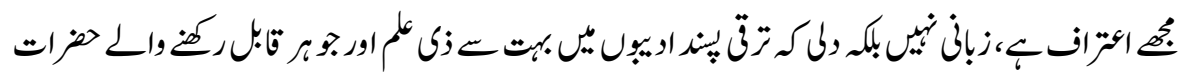

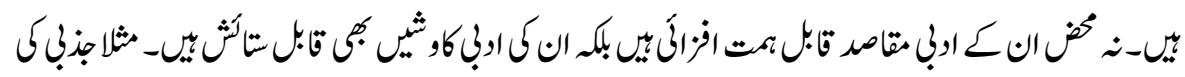

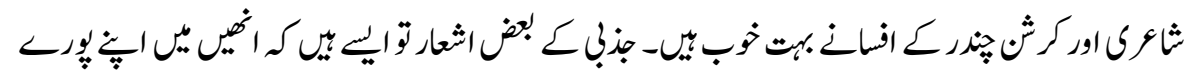




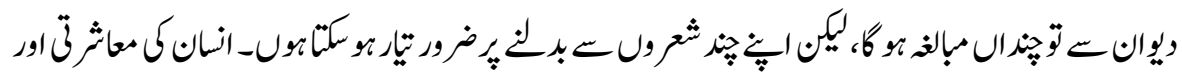

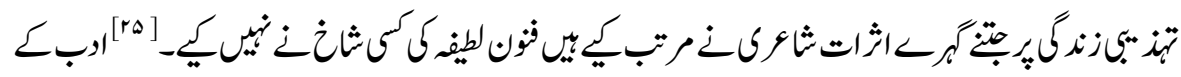

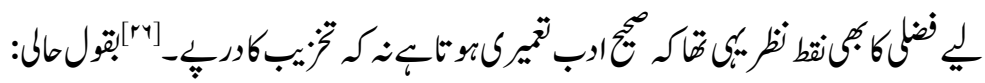

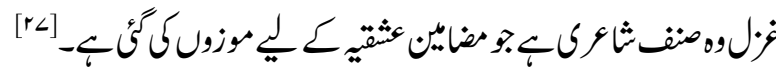

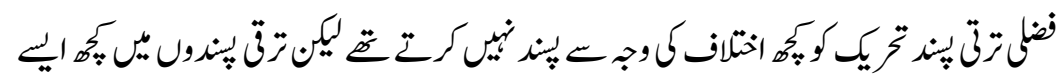

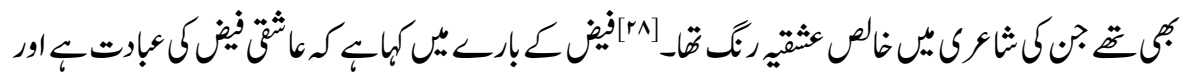

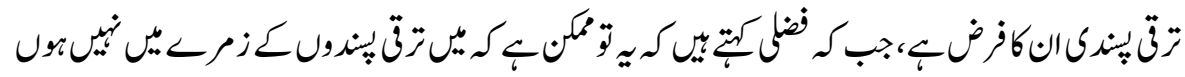

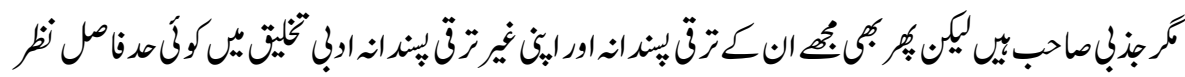

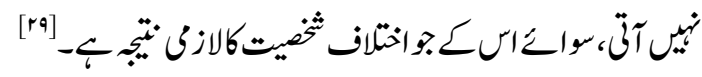

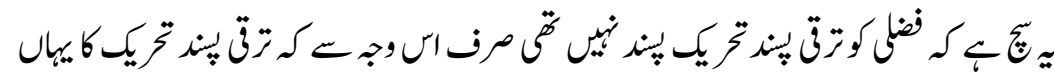

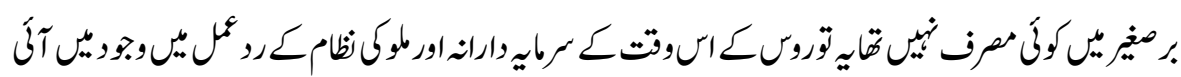

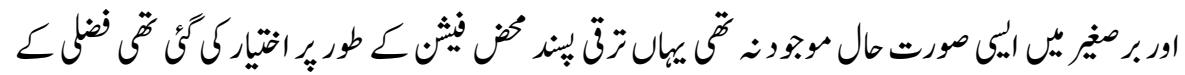

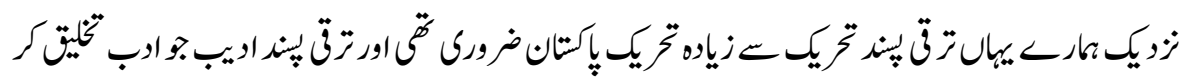

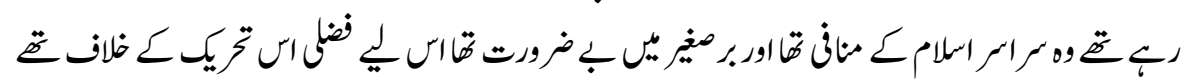

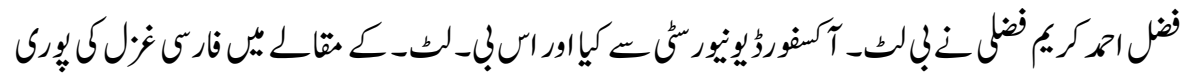

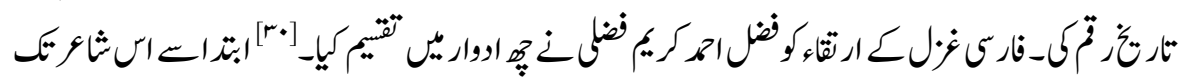

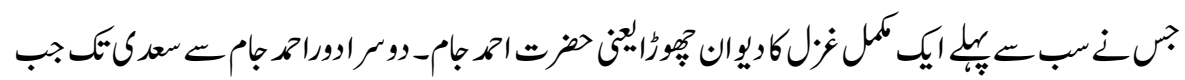

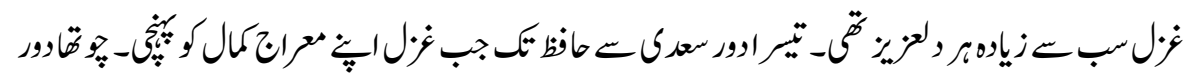

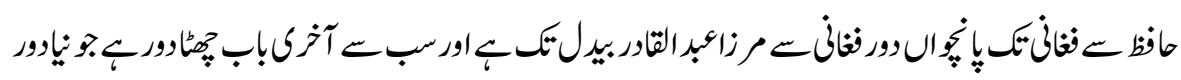

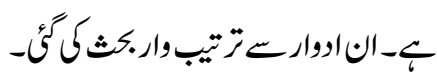

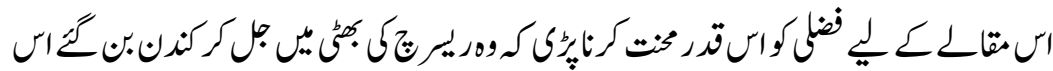

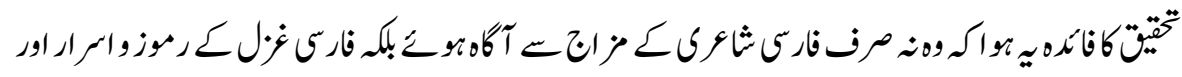

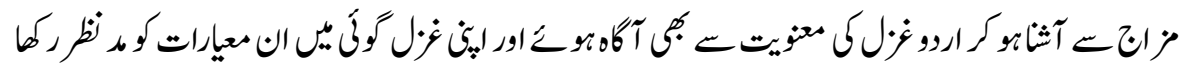


ISSN (Print): 2709-9636 | ISSN(Online) : 2709-9644 | ISSN-L : 2709-9636

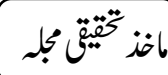

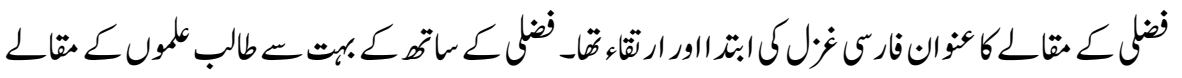

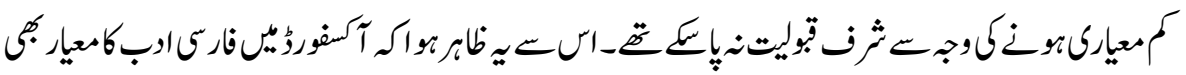

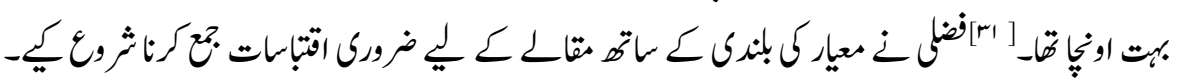

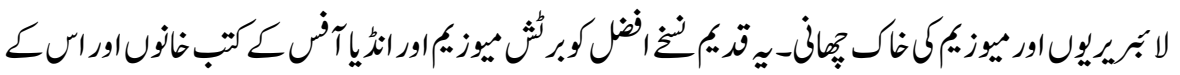

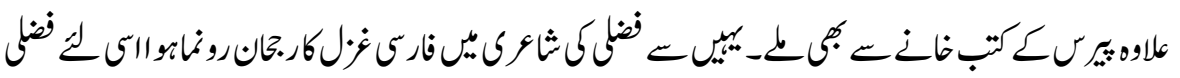

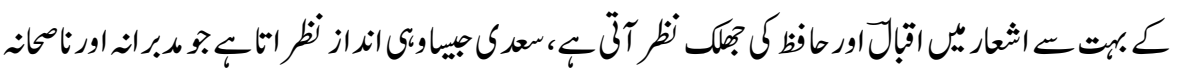

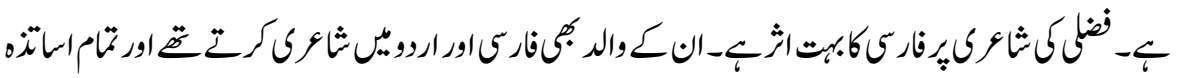

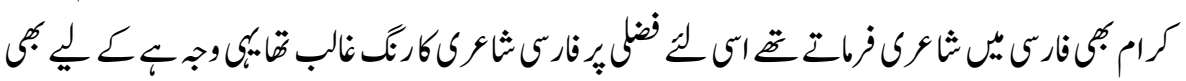

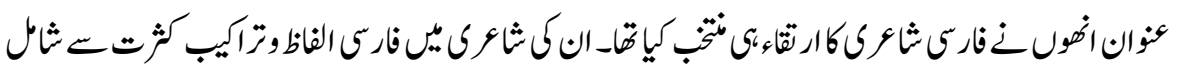

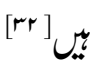

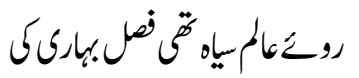

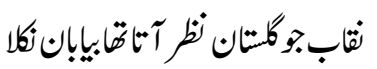

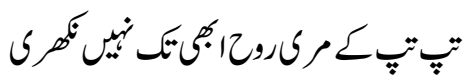

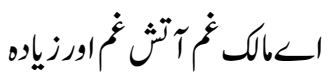

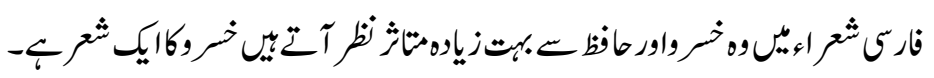

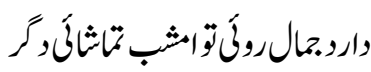

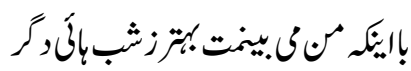

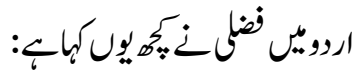

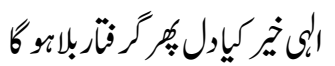

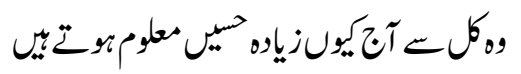

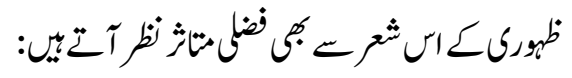

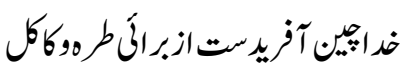

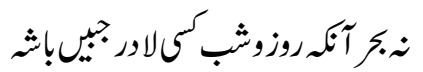

raM 


$$
\begin{aligned}
& \text { اروبيس تضنى ذاستيلبيان زمايا: }
\end{aligned}
$$

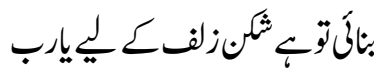

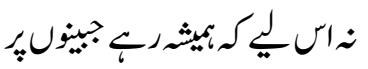

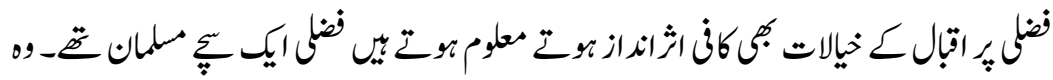

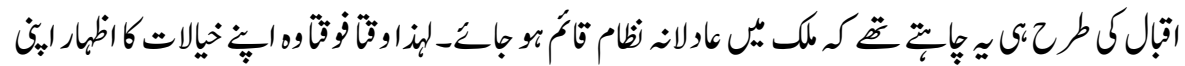

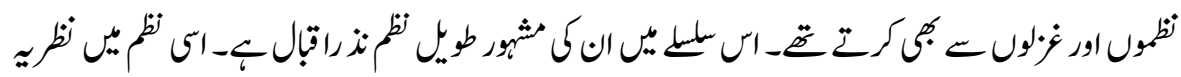

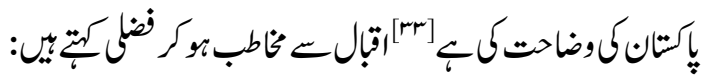

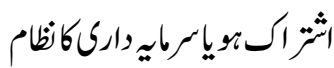

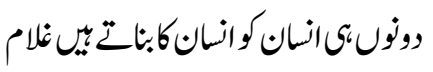

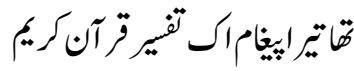

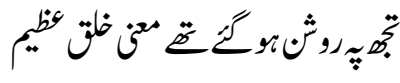

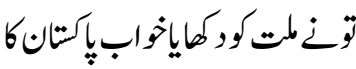

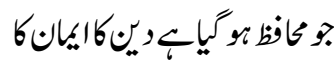

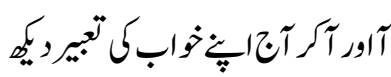

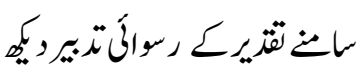

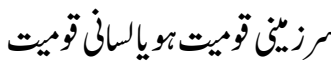

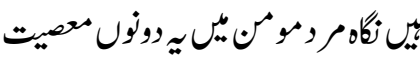

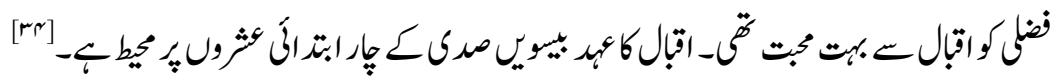

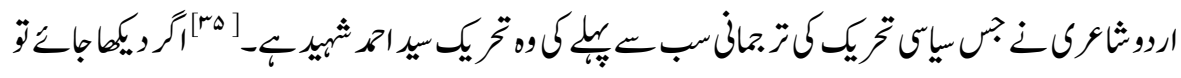

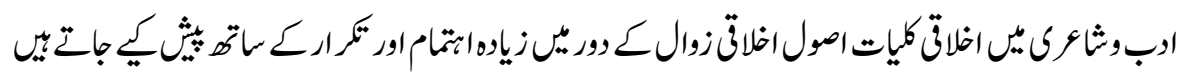

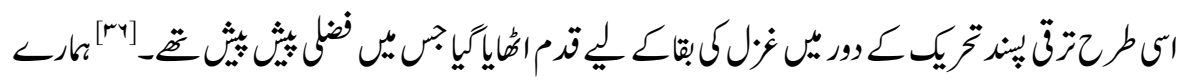

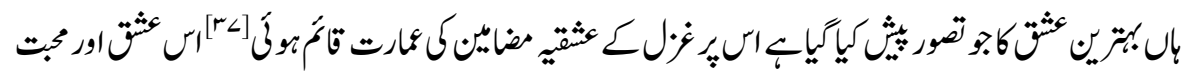




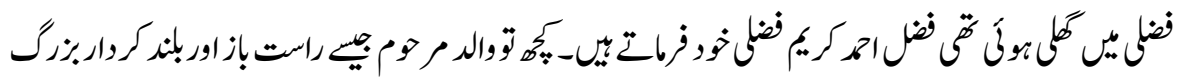

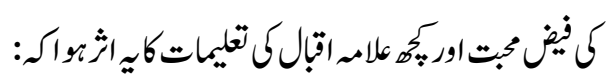
"ئنس

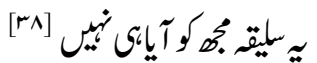

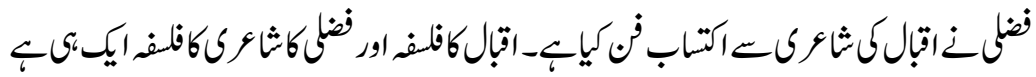

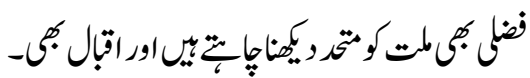

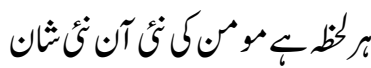
"ن:

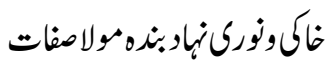

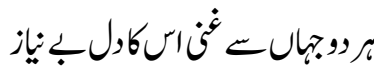

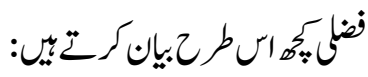

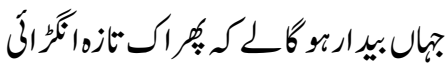

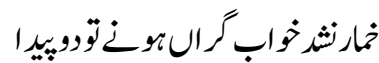

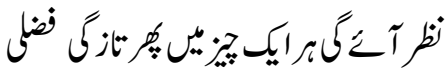

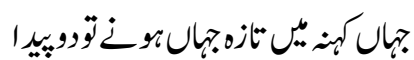

$$
\begin{aligned}
& \text { الـانات تثزكاقالوراع } \\
& \text { الوراعُورثلاق الوراع }
\end{aligned}
$$

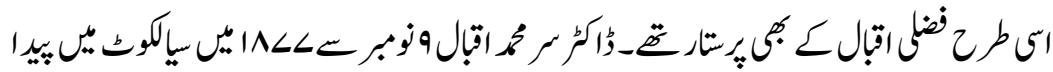

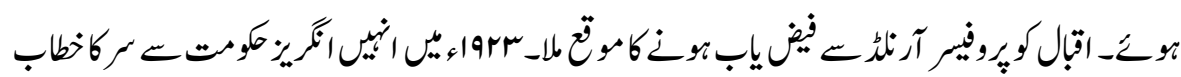

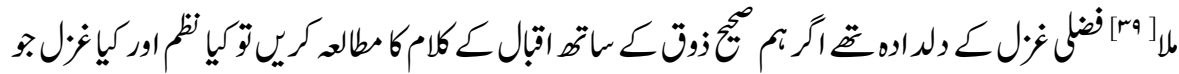

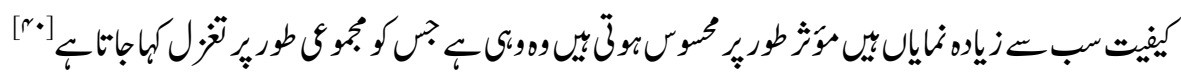

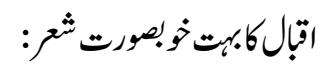

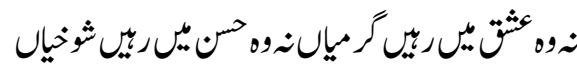




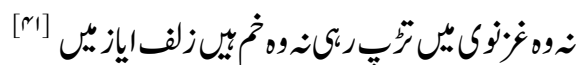

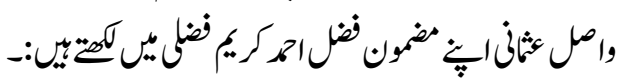

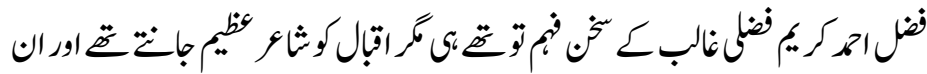

$$
\text { [مr] }
$$

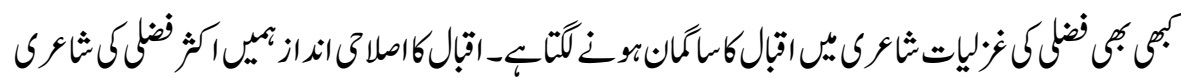

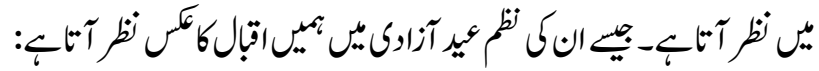

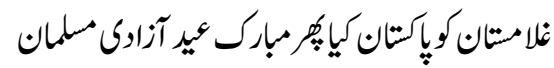

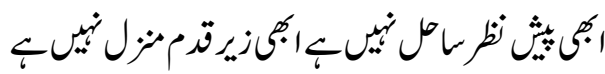

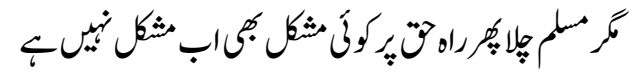

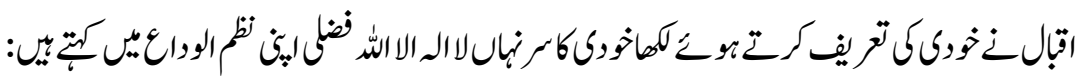

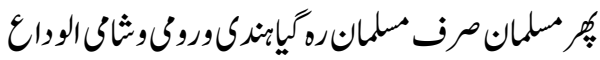

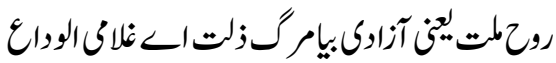

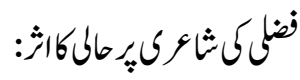

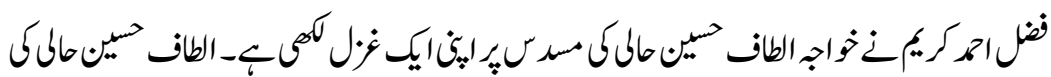

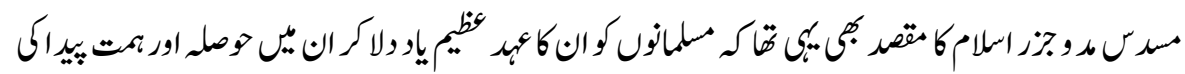

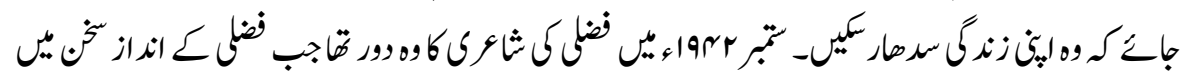

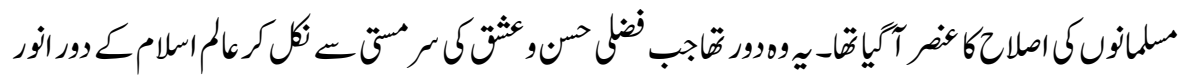

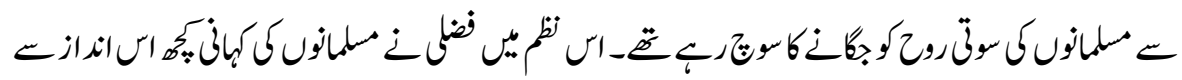

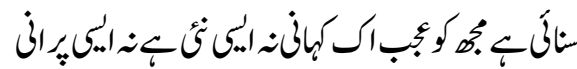

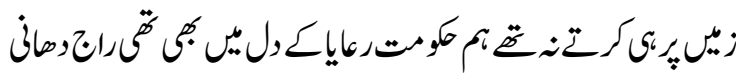

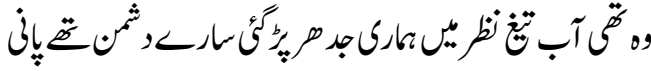




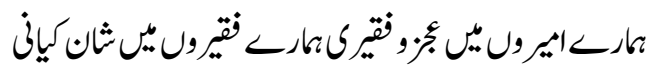

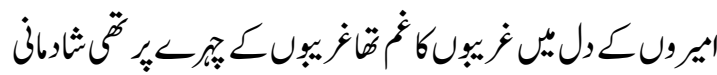

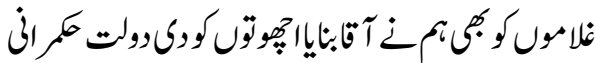

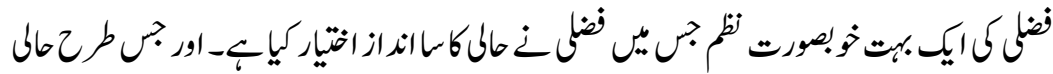

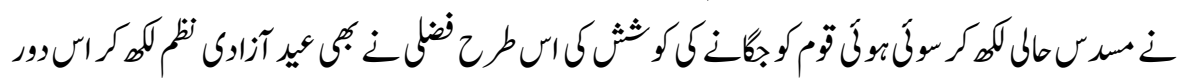

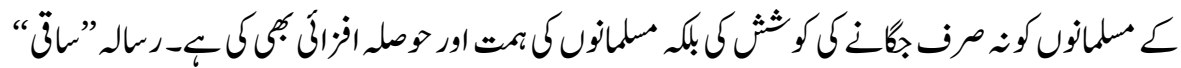

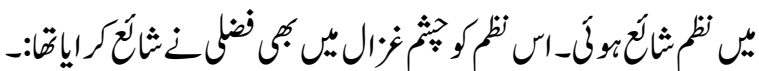

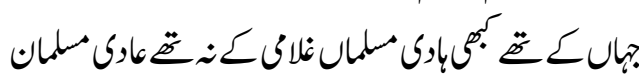

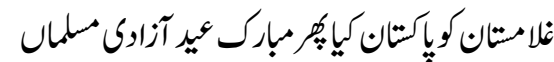

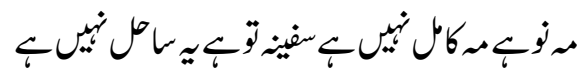

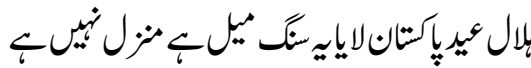

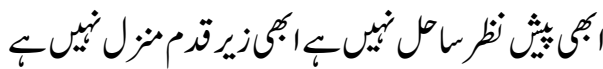

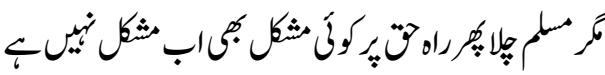

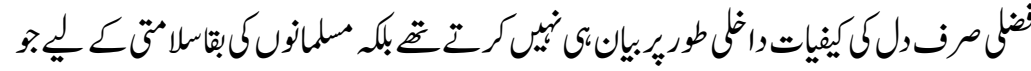

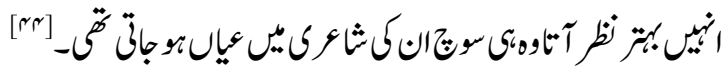

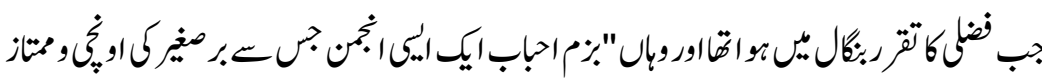

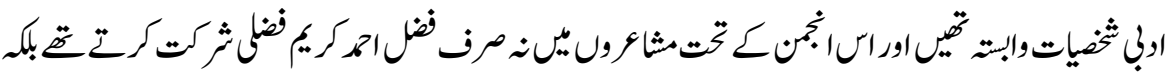

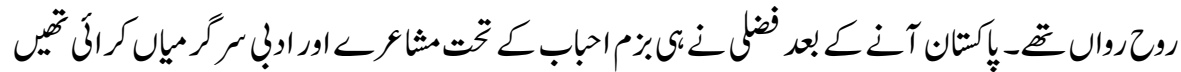

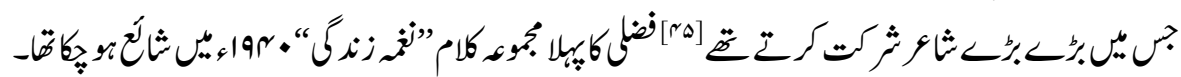

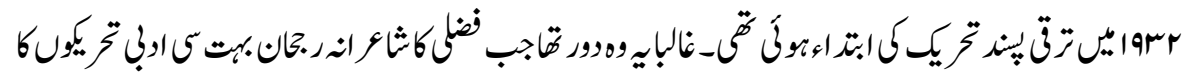

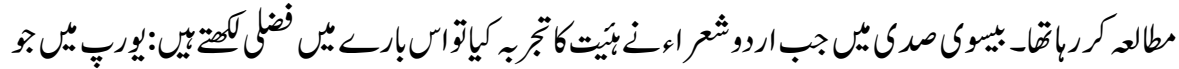

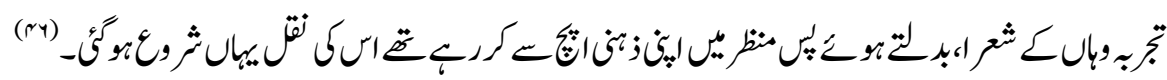


ISSN (Print): 2709-9636 | ISSN(Online) : 2709-9644 | ISSN-L : 2709-9636

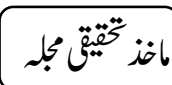

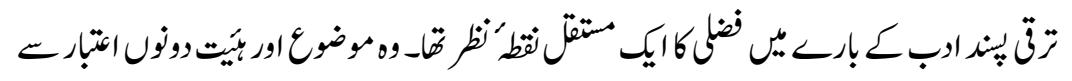

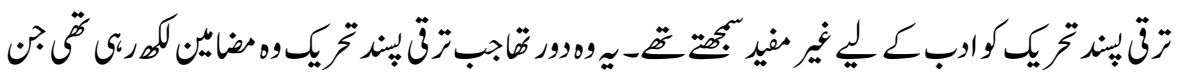

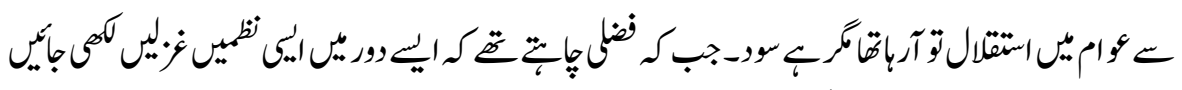

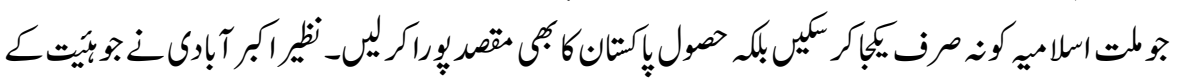

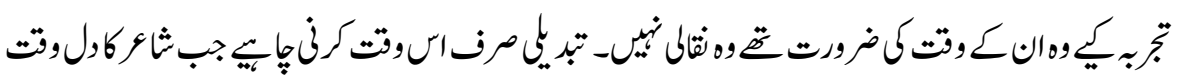

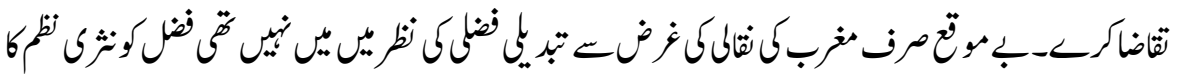

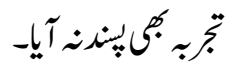

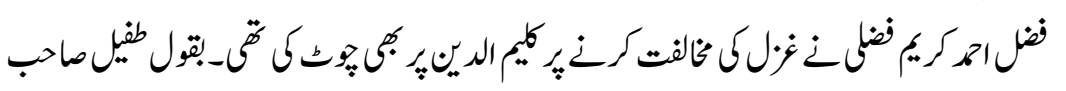

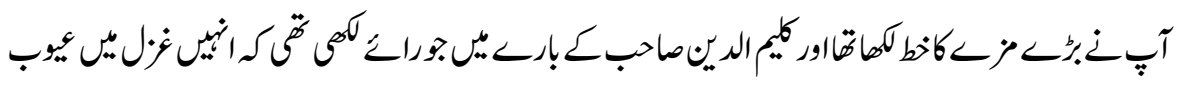

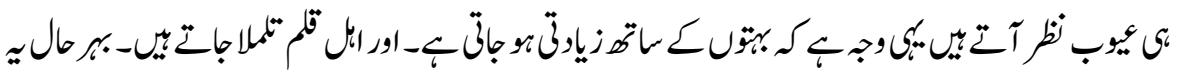

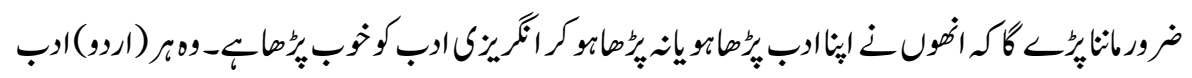

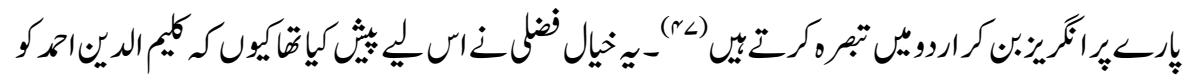

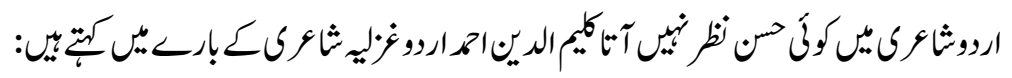

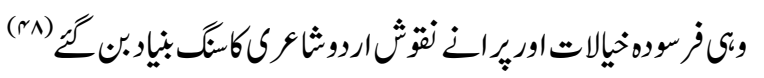

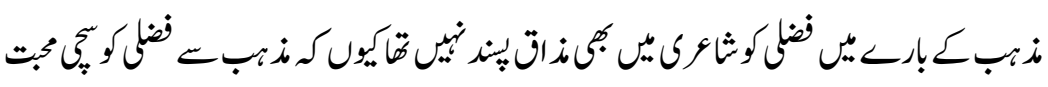

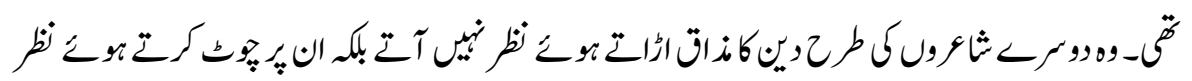

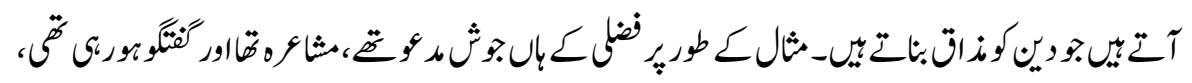

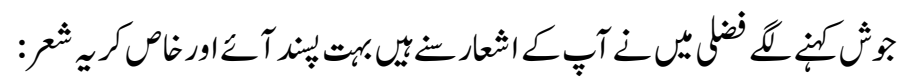

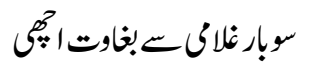

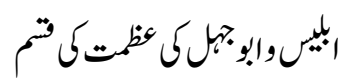

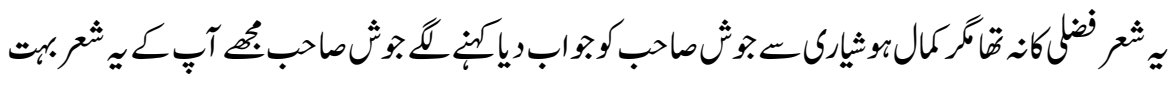

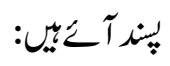

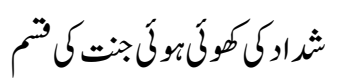

$\mu 41$ 


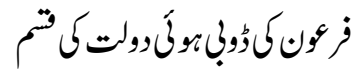

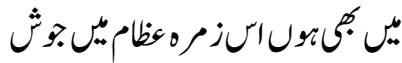

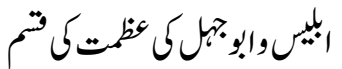

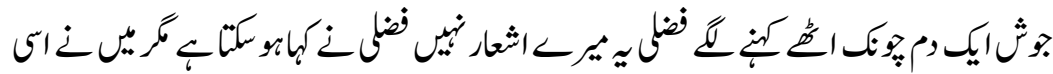

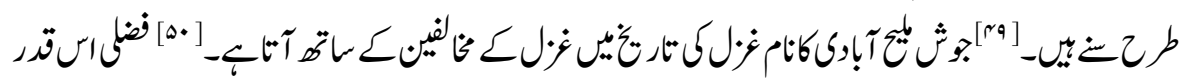

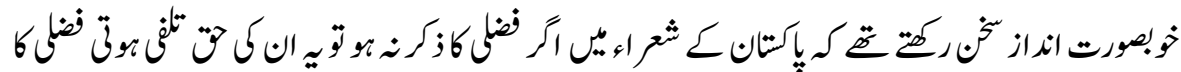

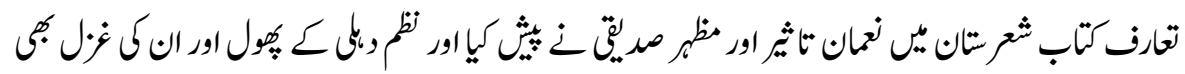

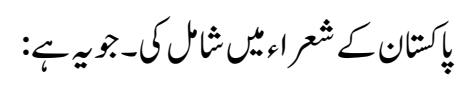

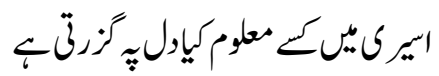

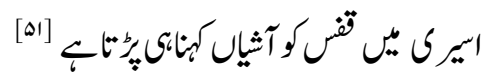

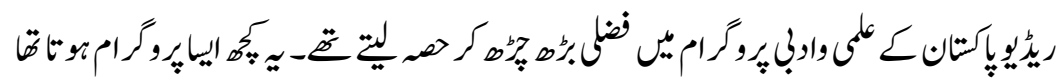

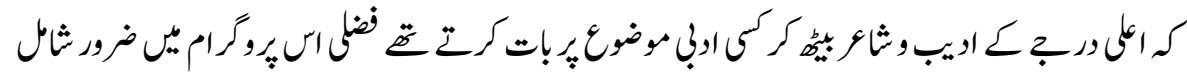

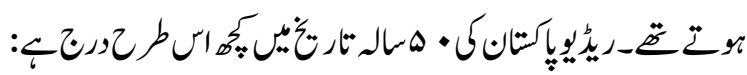

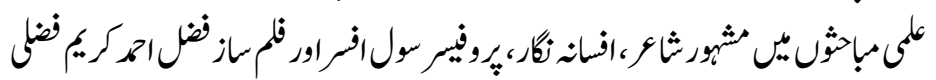

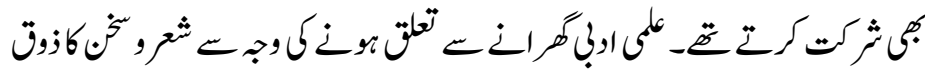

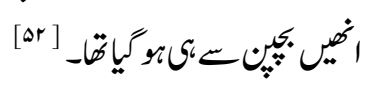

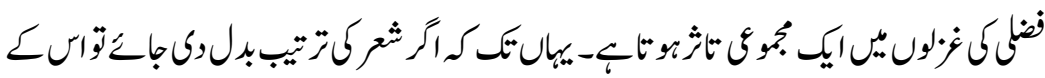

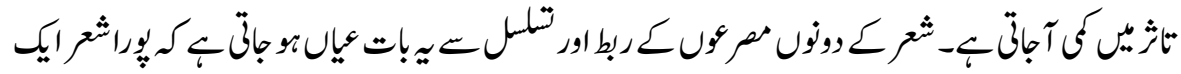

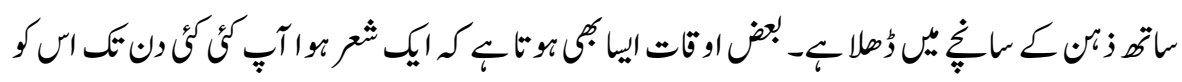

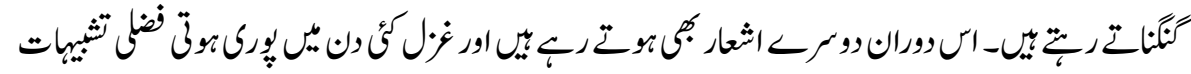

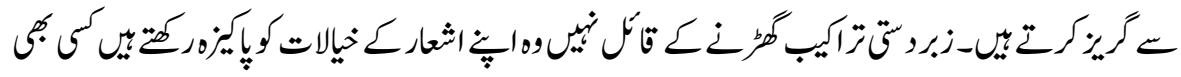

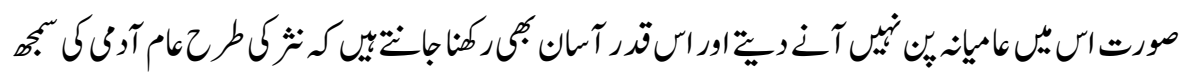

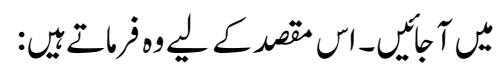




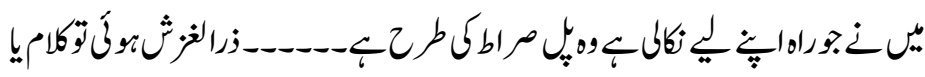

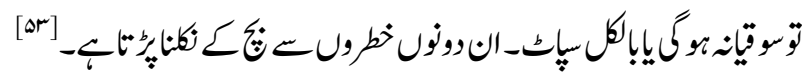

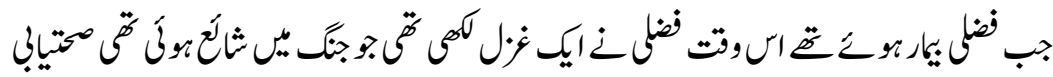

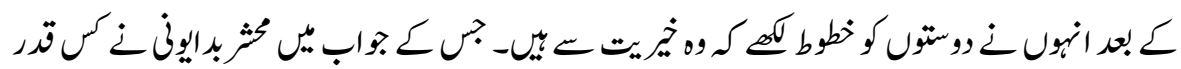

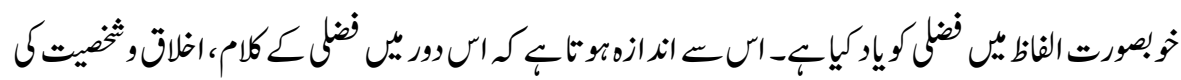

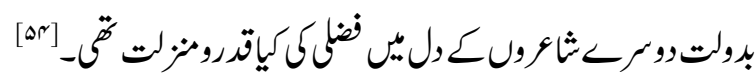

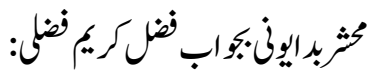

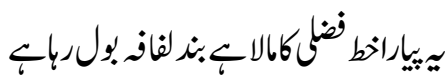

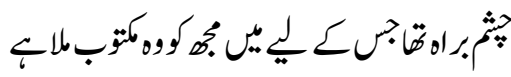

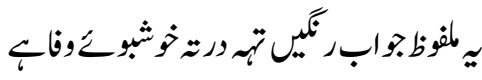

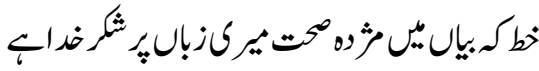

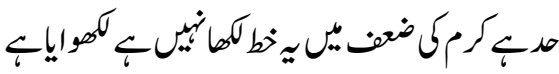

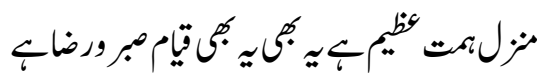

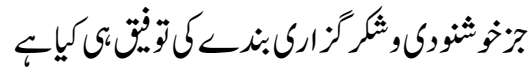

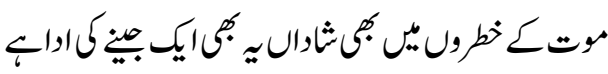

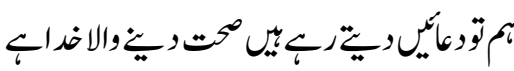

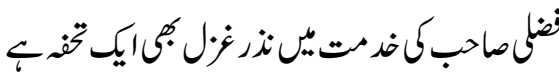

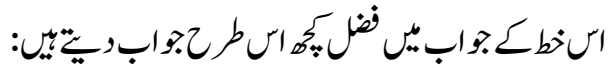
نضنيكواب كثربيوانظ:

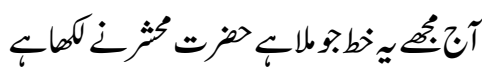

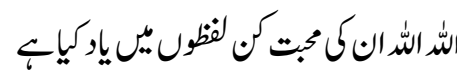

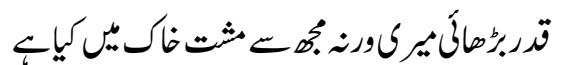


ISSN (Print): 2709-9636 | ISSN(Online) : 2709-9644 | ISSN-L : 2709-9636

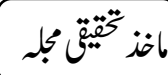

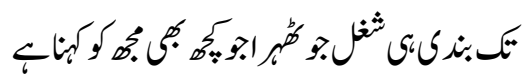

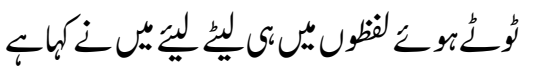

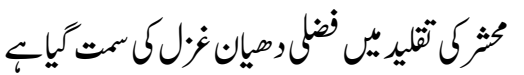

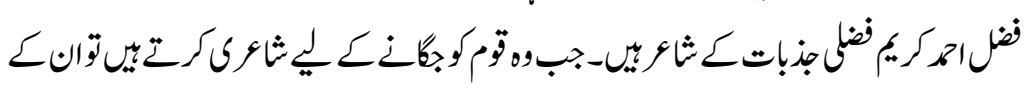

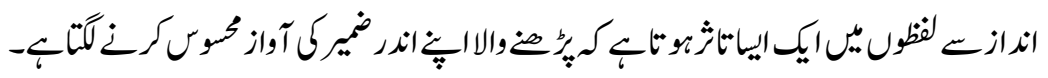

والرجات

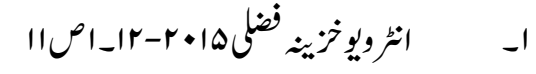

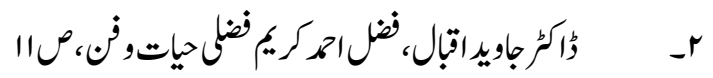

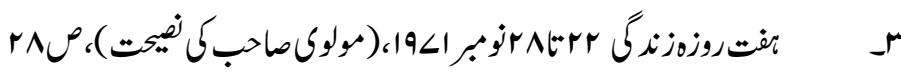

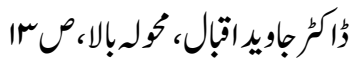

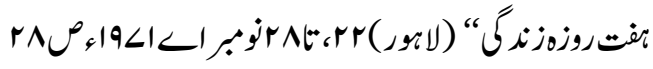

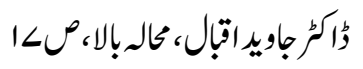

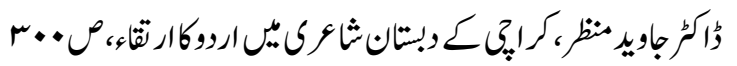

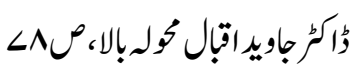

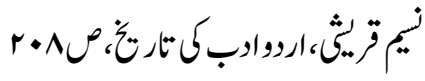

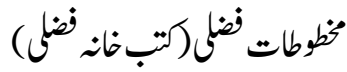

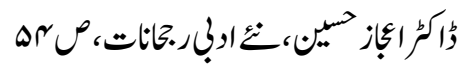

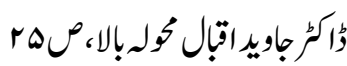

$$
\begin{aligned}
& \text { ساـ }
\end{aligned}
$$

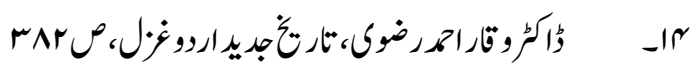

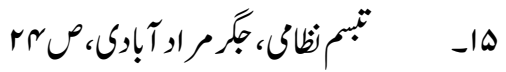

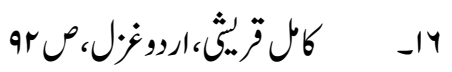

$$
\begin{aligned}
& \text { كاـ } \\
& \text { mys }
\end{aligned}
$$




$$
\begin{aligned}
& \text { ايضاـ } \\
& \text { 19 - ـ ايضا }
\end{aligned}
$$

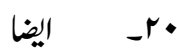

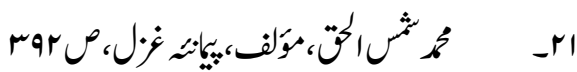

$$
\begin{aligned}
& \text { rr }
\end{aligned}
$$

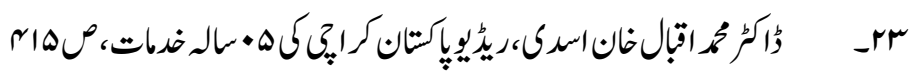

$$
\begin{aligned}
& \text { rr }
\end{aligned}
$$

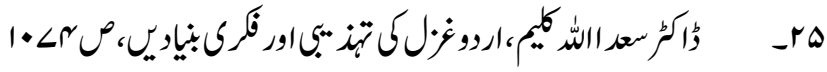

$$
\begin{aligned}
& \text { بry } \\
& \text { Lا }
\end{aligned}
$$

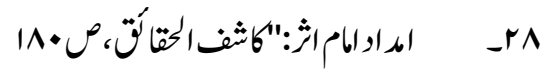

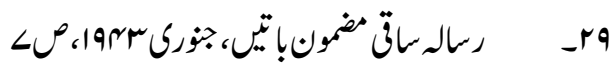

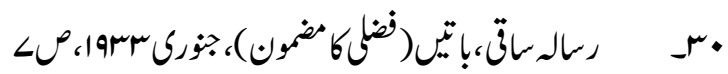

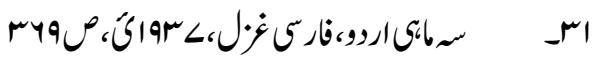

$$
\begin{aligned}
& \text { rr }
\end{aligned}
$$

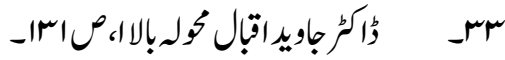

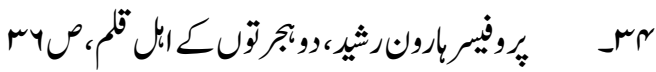

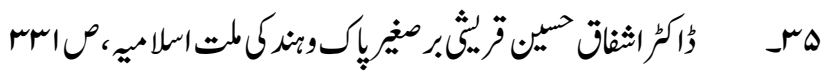

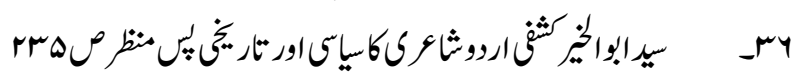

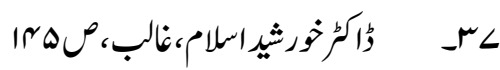

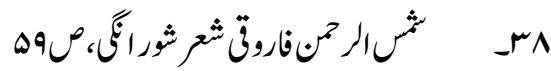

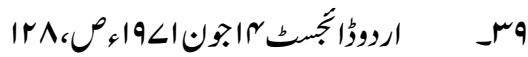

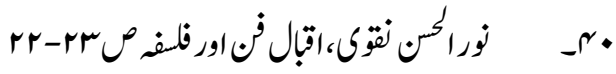




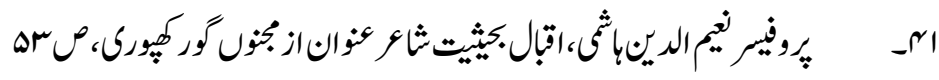

$$
\begin{aligned}
& \text { Ar }
\end{aligned}
$$

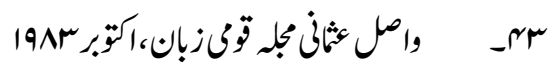

$$
\begin{aligned}
& \text { rr } \\
& \text { ه יم- }
\end{aligned}
$$

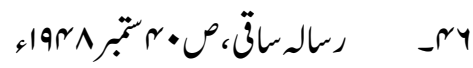

$$
\begin{aligned}
& \text { L 'r- }
\end{aligned}
$$

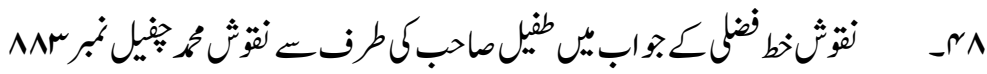

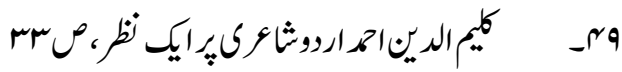

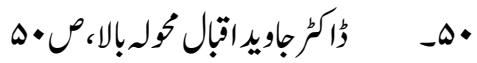

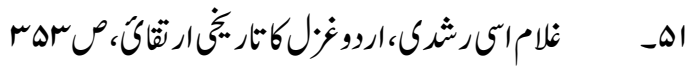

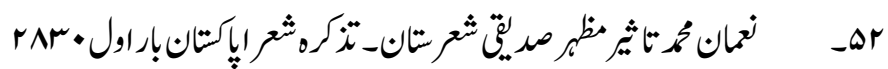

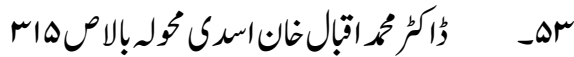

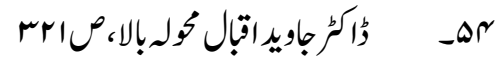

